\title{
ECONOMICA
}

Journal of Economic and Economic Education Vol.3 No.1 (64 - 70)

\section{PENGARUH TANGIBLE, EMPATHY, RELIABILITY, RESPONSIVENESSdan ASSURANCE TERHADAP LOYALITAS PELANGGAN BERBELANJA PADA TOKO TITA DI LUBUK BUAYA KOTA PADANG}

\author{
Hayu Yolanda Utami \\ Dosen Program Studi Pendidikan Ekonomi STKIP- PGRI Sumbar \\ Jl. Gunung Pangilun No.1, Padang Sumatera Barat \\ Email: hayuyudha@gmail.com \\ submited: 2014.06 .18 reviewed:2014.07.18 accepted: 2014.10 .30
http://dx.doi.org/10.22202/economica.2014.v3.i1.237
}

\begin{abstract}
This aim of the research is to analyze the Tangible, Empathy, Reliability, Responsiveness and Assurance can affect customer's loyality. The research is Quantitative and uses non-probability purposive sampling technique. The research using the model of multiple regression statistical analysis to determine the effects of independent variables and dependent variable and the assumption of classical test equipment to see if there are irregularities in the assumption of classical test.The result of the research showed that tangible, empathy, reliability, responsiveness and assurance have a significant impact either partiallyor in conjuction with the level of consumers loyality

Abstrak

Tujuan dari penelitian ini adalah untuk menganalisis Tangible, Empathy, Reliability, Responsiveness dan Jaminan dapat mempengaruhi loyalitas pelanggan. Penelitian ini Kuantitatif dan menggunakan non-probability teknik purposive sampling. Penelitian menggunakan model analisis statistik regresi berganda untuk menentukan dampak dari variabel independen dan variabel dependen dan asumsi alat uji klasik untuk melihat apakah ada penyimpangan dalam asumsi tes klasik. Hasil penelitian menunjukkan bahwa nyata, empati, keandalan, daya tanggap dan jaminan memiliki dampak yang signifikan baik secara parsial maupun dalam conjuction dengan tingkat konsumen loyalitas
\end{abstract}

Keywords : Tangible, Empathy, Reliability, Responsiveness, Assurance and consumers loyality 


\section{PENDAHULUAN}

Dalam dunia bisnis terutama bisnis jasa seperti mini market, supermarket dan toko harus sangat mengutamakan pelayanan kepada pelanggan karena tingginya tingkat persaingan didalam bisnis tersebut. Ditandai dengan semakin menjamurnya bisnis yang sama ditengah-tengah masyarakat karenamerupakan kebutuhanmasyarakat perkotaan yang modern dan hanya membutuhkan waktu singkat dalam berbelanja. Kebutuhan primer untuk berbelanja terkadang dijadikan sarana refreshing bagi para konsumen, kegiatan yang dilakukan konsumen setiap bulan atau mingguan ini merupakan salah satu kebutuhan wajib bagi konsumen untuk dapat memiliki barang-barang kebutuhan sehari-hari yang dibutuhkan. Toko Tita merupakan minimarket yang terletak di daerah Lubuk Buaya Kota Padang yang menyediakan beraneka ragam kebutuhan pokok seharihari bagi konsumen. Toko Tita sangat memperhatikan kualitas pelayanan sebagai kunci dalam memperthankan dan meningkatkan pelanggan. Untuk itu penting bagi Toko Tita atau sebagai penyedia jasa dapat memperhatikanpelayanannya kepada pelanggan agar dapat memberikan kepuasan bagi pelanggan sehingga pelanggan dapat tetap loyal pada toko atau mini market tersebut.

Pelayanan yang tepat dan berkualitas serta mengena dan di ingat dihati konsumen sehingga membuat konsumen nyaman merupakan perilaku produsen dalam rangka memenuhi kebutuhan dan keinginan konsumen ataupun pelanggan demi tercapainya kepuasaan bagi pelanggan sehingga dapat menimbulkan kesetiaan bagi pelanggan walaupun mungkin ada penawaran lain yang lebih menarik tapi pelanggan tidah berpindah. Menurut Lovelock (dalam Tjiptono, 2000 : 58) kualitas pelayaanan merupakan tingkatan kondisi baik buruknya sajian yang diberikan oleh perusaahaan jasa dalam rangka memuaskan konsumen dengan cara memberikan atau menyampaikan jasa yang melebihi harapan konsumen.Pada prinsipnya, setiap bisnis harus mampu memuaskan dan mempertahankan pelanggan. Hal ini merupakan kunci untuk mempertahankan kinerja bisnis. Dengan memberikan kepada pelanggan "No Reason to Switch and Every Reason to Stay berarti bisnis atau perusahaan telah mengisolasi mereka dari tekanan kompetisi (Johnson \& Gustafsson, 1997 : 121). Pentingnya kualitas pelayanan untuk dapat membuat pelanggan setia atau loyal pada toko tertentu harus benar-benar dipertahankan dan diperbaiki menjadi semakin baik agar bisnis atau toko tersebut dapat memiliki pelanggan setia dan menambah pelanggan-pelanggan baru dimasa yang akan datang karena pelanggan merupakan kunci kesuksesan dan kelanggengan suatu usaha atau bisnis. Kesetiaan atau loyalitas pelanggan dapat menarik konsumen lain untuk mengikuti karena adanya promosi dari mulut ke mulut sehingga menarik konsumen baru yang dapat menjadi pelanggan setia berikutnya.

Loyalitas pelanggan merupakan tujuan inti yang diupayakan pemasar dalam mempertahankan dan meningkatkan pelanggan. Hal ini dikarenakan dengan loyalitas yang sesuai dengan yang diharapkan maka dipastikan akan memberikan keuntungan di saat ini dan masa yang akan datang. Dalam jangka panjang, loyalitas pelanggan menjadi tujuan bagi perencanaan strategik sebagai dasar pengembangan keunggulan yang kompetitif yang berkelanjutan (Hasan, 2013: 120). Konsep loyalitas pelanggan tidak terbentuk sesaat, ini butuh proses berdasarkan pengalaman pembelian konsisten pelanggan tersebut dan tentunya ini tidak mudah bagi produsen atau pemilik toko atau minimarket, butuh kerja keras karena tingginya tingkat persaingan dan mudahnya pelanggan untuk pindah. Konsumen sebagai raja akan membandingkan dan mencari tempat berbelanja yang sesuai dengan keinginannya sehingga tidak mustahil bagi mereka untuk berpindah-pindah tempat 
berbelanja agar mendapatkan tempat berbelanja sesuai dengan keingingannya dan dapat memuaskannya sebelum mereka memutuskan untuk loyal pada satu toko yang bisa jadi loyalitas itu terbentuk karena jarak jangkau serta kemudahan akses ke toko dan kesempatan tersebut harus dimanfaatkan pemilik dan karyawan toko untuk dapat membuat pelanggan puas sehingga loyal dan nyaman berbelanja. Untuk itu perlunya para pemasar atau produsen memiliki pengetahuan dan pemahaman tentang pentingnya untuk tetap meningkatkan kualitas pelayanan secara konsisten untuk dapat mempertahankan atau meningkatkan loyalitas pelanggan dari waktu ke waktu.

\section{Hubungan Tangible terhadap Loyalitas Pelanggan}

Menurut Tjiptono (2008 : 95) Tangible berkenaan dengan penampilan fisik fasilitas pelayanan, peralatan/ perlengkapan, sumber daya manusia dan materi komunikasi perusahaan berkaitan secara langsung dengan indikator-indikator loyalitas pelanggan.

\section{Hubungan Emphaty terhadap Loyalitas Pelanggan}

Menurut Tjiptono (2008 : 95) emphaty berarti perusahaan memahami masalah pelanggannya dan bertindak demi kepentingan pelanggan, berpengaruh secara positif dimensi loyalitas pelanggan yaitu tetap memilih merek tersebut, merekomendasikannya kepada orang lain dan melakukan pembelian secara ulang.

Hubungan Reliability terhadap Loyalitas Pelanggan

Menurut Tjiptono (2008 : 96) indikator dari reliabilityterdiri dari konsistensi kerja (performance) dan sifat terpecaya (Dependability) yang positif berpengaruh langsung dengan dimensi loyalitas pelanggan yaitu menyatakan hal yang positif (Say Positif Things) memberikan rekomendasi kepada orang lain (Recommend Friend) dan melakukan pembelian terus menerus (Continue Purchasing).

Hubungan Responsiveness terhadap Loyalitas Pelanggan
Menurut Tjiptono (2008 : 96) responsiveness yaitu kesediaan dan kesigapan para karyawan untuk membantu dan melayani pelanggan dengan segera, berpengaruh secara langsung dan positif terhadap loyalitas pelanggan. Karena memberikan nilai plus berupa motivasi khusus bagi para pelanggan untuk menjalin ikatan relasi saling menguntungkan dalam jangka panjang.Ikatan inilah yang menjadikan pelanggan menjadi loyal.

\section{Hubungan Assurance terhadap Loyalitas Pelanggan}

Menurut Tjiptono (2008 : 97) assurance berkenaan dengan pengetahuan personality karyawan serta kemampuan mereka dalam menumbuhkan rasa percaya diri (trust) dan keyakinan pelanggan (confidence), memberikan kontribusi positif terhadap terwujudnya loyalitas pelanggan. Karena pelanggan merasa dimengerti dan akhirnya merasa nyaman sehingga membuat pelanggan tersebut menjadi loyal.

Studi sebelumnya yang dilakukan oleh Cornelia Ellys dan Kartika Wijaya (2008) tentang Analisis Pengaruh Kualitas Layanan terhadap Loyalitas Pelanggan di Laundry 5ASEC Surabaya, dengan hasil penelitian bahwa Kualitas Layanan berpengaruh secara signifikan terhadap Loyalitas Pelanggan.

Aryani, Dwi (2010) tentang Pengaruh Kualitas Layanan Terhadap Kepuasan Pelanggan dalam Membentuk Loyalitas Pelanggan dengan hasil penelitian bahwa terdapat pengaruh secara signifikan antara kualitas pelayanan dengan kepuasan pelanggan dan antara kualitas layanan terhadap loyalitas pelanggan yang ditunjukkan oleh $91 \%$ variabel loyalitas pelanggan yang dapat dijelaskan oleh kualitas layanan sedangkan sisanya 9\% dipengaruhi oleh variabel lain diluar kualitas layanan.

Berdasarkan latar belakang tersebut maka tujuan dari penelitian ini adalah untuk melihat bagaimana pengaruh Tangible, Emphaty, Reliability, Responsiveness dan Assurance secara parsial dan simultanterhadap Loyalitas Pelanggan. 
Populasi adalah wilayah generalisasi yang terdiri atas obyek/ subyek yang mempunyai kualitas dan karakteristik tertentu yang ditetapkan oleh peneliti untuk dipelajari dan kemudian ditarik kesimpulannya (Sugiyono, 2013: 80). Dalam penelitian ini yang akan menjadi populasi adalah semua pelanggan yang berbelanja di Toko Tita secara berulangulang yang tidak diketahui jumlahnya secara pasti.

Sampel adalah bagian dari jumlah dan karakteristik yang dimiliki oleh populasi tersebut (Sugiyono, 2013: 81). Karena jumlah sampel tidak diketahui secara pasti atau tidak terbatas maka untuk menentukan ukuran sampek digunakan pendapat Rescue (1978) dalam Sekaran (2011 : 160) yang menyatakan bahwa ukuran sampel yang baik adalah $10 \times$ jumlah variabel. Jadi jumlah sampel yang dikumpulkan berjumlah $(10 \times 6)=60$. Jadi total responden yang akan dijadikan sampel adalah 60 orang. Untuk mendapatkan jumlah sampel sesuai dengan ukuran yang dinyatakan tersebut maka digunakan teknik Purposive Sampling.Menurut Jogiyanto (2007) teknik Purposive Sampling dilakukan dengan mengambil sampel dari populasi berdasarkan suatu kriteria tertentu. Kriteria responden yang digunakan didalam penelitian ini meliputi :

1. Konsumen yang melakukan pembelian ulang secara teratur dan tidak tertarik untuk berbelanja di toko atau minimarket lainnya untuk membeli kebutuhan hariannya.

2. Konsumen yang berdomisili di kota Padang.

Data penelitian ini adalah data primer dan data sekunder. Data primer dalam penelitian ini dengan mengajukan daftar pertanyaan tertutup berupa kuesioner kepada responden.Responden yang dipilih adalah responden yang berbelanja di Toko Tita Lubuk Buaya Padang sesuai dengan kriteria yang telah ditetapkan. Pengambilan data dilakukan dengan cara memberikan kuesioner secara langsung kepada responden.
Variabel yang digunakan dalam penelitian ini terdiri dari :

1. Variabel independen (variabel Bebas)

a. Tangible (Berwujud) sebagai variabel X1, yang terdiri dari :

- Kebersihan fasilitas fisik, Kerapihan penampilan karyawan dan kemutakhiran (modern) sarana fisik yang dimiliki (Cronin \& Taylor, 1994).

b. Empathy (Empati) sebagai variabel $\mathrm{X} 2$, yang terdiri dari :

- Perhatian secara personal oleh pemilik dan karyawan, Mudah diakses dan memperhatikan kebutuhan pelanggan dengan sungguh-sungguh (Cronin \& Taylor, 1994).

c. Reliability (Kehandalan) sebagai variabel X3, yang terdiri dari :

- Menyediakan jasa pelayanan dengan baik dari awal hingga akhir, keakuratan penanganan atau pengadministrasian catatan atau dokumen seperti struk pembelian dan pelayanan sesuai dengan yang dijanjikan (Cronin \& Taylor, 1994).

d. Responsiveness (Daya Tanggap) sebagai sebagai $\mathrm{X} 4$, yang terdiri dari :

- Kesediaan karyawan dan pemilik dalam memberikan layananan cepat, kesediaan karyawan dan pemilik dalam membantu kesulitan pelanggan dengan cepat dan keluangan waktu karyawan dan pemilik untuk menanggapi permintaan konsumen dengan cepat (Cronin \& Taylor, 1994).

e. Assurance (Jaminan) sebagai variabel $\mathrm{X} 5$, yang terdiri dari :

- Reputasi yang terjamin, kompetensi (kemampuan) karyawan dalam bidang pelayanan dan keramahan karyawan dan pemilik dalam memberikan layanan (Cronin \& Taylor, 1994).

2. Variabel Dependent (variabel Terikat) 
Loyalitas Pelanggan, sebagai variabel Y yang tediri dari :

- Pelanggan mengatakan hal positif , pelanggan memberikan rekomendasi kepada pihak lain untuk berbelanja, kemungkinan besar pelanggan akan berbelanja lagi, pelanggan jarang melakukan peralihan ke toko atau mini market lainnya, Usaha atau bisnis merupakan pilihan pertama jika pelanggan ingin berbelanja dan pelanggan percaya merupakan tempat berbelanja kebutuhan sehari-hari yang terbaik (Gremler \& Brown, 1996).

Metode analisis yang digunakan adalah regresi linear berganda.Metode ini digunakan untuk mengetahui ada tidaknya pengaruh antara variabel independen tdan variabel dependent (Singgih, 2005).Analisis regresi berganda dilakukan dengan menggunakan computer. Perangkat lunak yang digunakan adala SPSS for window release 15 . Maka dapat dirumuskan persamaan regresi berganda yang dikemukakan Gujarati (1997) :

$$
\mathrm{Y}=\mathrm{a}+\beta 1 \mathrm{X} 1+\beta 2 \mathrm{X} 2+\beta 3 \mathrm{X} 3+
$$

$\beta 4 \mathrm{X} 4+\beta 5 \mathrm{X} 5+\mathrm{e}$

Dimana :

Y $\quad$ L Lyalitas

Pelanggan.

A $\quad=$ Konstanta.

$\beta 1, \beta 2, \beta 3, \beta 4, \beta 5 \quad=$ Koefisien Regresi

Tangible, Emphaty,

Reliability,

Responsiveness dan

Assurance

$\mathrm{X} 1$

$\mathrm{X} 2$

$\mathrm{X} 3$

$\mathrm{X} 4$

$\mathrm{X} 5$

$\mathrm{e}$

= Tangible

= Emphaty

$=$ Reliability

$=$ Responsiveness

= Assurance

$=$ Error

Untuk menguji secara parsial antara variabel independent terhadap variabel dependent dengan variabel lain dianggap konstan, dengan asumsi jika signifikan nilai t-hitung dan F-hitung yang dapat dilihat dari hasil analisis regresi bergandamenujukkan besar dari $\alpha=5 \%$ (Sugiyono, 2005).

\section{PEMBAHASAN}

Pengaruh variabel Tangible, Emphaty, Relaibility, Responsiveness dan Assurancesecara parsial terhadap loyalitas pelanggan dijelaskan melalui persamaan regresi sebagai berikut :

$$
\mathrm{Y}=75.473+0.224 \mathrm{X} 1+0.238 \mathrm{X} 2
$$

$+0.226 \mathrm{X} 3+0.225 \mathrm{X} 4+0.229 \mathrm{X} 5+\mathrm{e}$

Berdasarkan pengujian hipotesis, dapat ditarik kesimpulan tentang pengaruh masing-masing variabel bebas secara individu (parsial) terhadap variabel terikat sebagai berikut :

a. Koefisien regresi variabel Tangible (Bukti Fisik) sebesar0.224 dan hasil analisis Uji $\mathrm{t}$ diketahui nilai sig sebesar 0.000 , dari hasil tersebut dapat diketahui $\operatorname{sig}(0.000)<\alpha(0,05)$ artinya H0 ditolak dan Ha diterima. Dengan demikian dapat disimpulkan bahwa secara parsial atau individu variabel Tangible (bukti fisik) berpengaruh positif dan signifikan terhadap loyalitas pelanggan. Hal ini berarti semakin baik tangible (bukti fisik) berupa kebersihan toko dan kerapihan susunan barang, kerapihan penampilan karyawan seperti pakaian dan rambut yang terikat rapi dan kemutakhiran sarana (modern) dan prasarana seperti adanya fasilitas wifi dan parkiran yang luasmaka akan semakin meningkat loyalitas pelanggan pada Toko Tita Lubuk Buaya Padang.

b. Koefisien regresi variabel Emphaty (Empati) sebesar 0.238 dan hasil analisis Uji t diketahui nilai sig sebesar 0.004 , dari hasil tersebut dapat diketahui sig $(0.004)<$ $\alpha(0,05)$ artinya $\mathrm{H} 0$ ditolak dan $\mathrm{Ha}$ diterima. Dengan demikian dapat disimpulkan bahwa secara parsial atau individu variabelEmphaty(Empati) berpengaruh positif dan signifikan terhadap loyalitas pelanggan. Hal ini berarti semakin tinggi Emphaty (Empati) berupa perhatian secara personal oleh pemilik dan karyawan seperti karyawan melayani dengan sepenuh hati dan penuh senyuman apabila pelanggan bertanya tentang suatu produk yang dibutuhkan 
pelanggan serta menolong pelanggan tanpa harus diminta oleh pelanggan, toko mudah diakses seperti jarak yang dekat dan mudahnya angkutan umum untuk menuju ketoko dan memperhatikan kebutuhan pelanggan dengan sungguh-sungguh maka akan semakin meningkat loyalitas pelanggan pada Toko Tita Lubuk Buaya Padang.

c. Koefisien regresi variabel Reliability (Kehandalan) sebesar 0.226 dan hasil analisis Uji $\mathrm{t}$ diketahui nilai sig sebesar 0.001, dari hasil tersebut dapat diketahui sig $(0.001)<\alpha(0,05)$ artinya $\mathrm{H} 0$ ditolak dan Ha diterima. Dengan demikian dapat disimpulkan bahwa secara parsial atau individu variabel Reliability (Kehandalan) berpengaruh positif dan signifikan terhadap loyalitas pelanggan. Hal ini berarti semakin meningkatReliability (Kehandalan) berupa memberikan jasa pelayanan secara baik dari awal hingga akhir seperti kehandalan dan keramahan karyawan, keakuran struk pembelian seperti pelanggan selalu mendapatkan struk belanja sesuai dengan barang-barang yang dibeli pelanggan dan harga yang bayar pelanggan sesuai yang tertera di barang dan struk belanja maka akan semakin meningkat loyalitas pelanggan pada Toko Tita Lubuk Buaya Padang.

d. Koefisien regresi variabel Responsiveness (Daya Tanggap) sebesar 0.225 dan hasil analisis Uji t diketahui nilai sig sebesar 0.004, dari hasil tersebut dapat diketahui sig $(0.004)<\alpha(0,05)$ artinya $\mathrm{H} 0$ ditolak dan Ha diterima. Dengan demikian dapat disimpulkan bahwa secara parsial atau individu variabel Responsiveness (Daya Tanggap) berpengaruh positif dan signifikan terhadap loyalitas pelanggan. Hal ini berarti semakin tinggi Responsiveness (Daya Tanggap) berupa kesediaan pemilik dan karyawan dalam memberikan layanan secara cepat kepada pelanggan tanpa harus diminta oleh pelanggan dan tidak adanya karyawan yang mengobrol sesama karyawan dan cuek kepada pelanggan, kesediaan pemilik dan karyawan dalam membantu kesulitan pelanggan dengan secara cepat tanpa membuat pelanggan harus menunggu dan keluangan waktu karyawan dan pemilik untuk menanggapi permintaan konsumen dengan cepat tanpa mementingkan pekerjaannya yang lain yang berarti karyawan harus menghentikan pekerjaannya yang tidak berhubungan dengan pelayanan terhadap pelanggan maka akan semakin meningkat loyalitas pelanggan pada Toko Tita Lubuk Buaya Padang.

e. Koefisien regresi variabel Assurance (Jaminan) sebesar 0.229dan hasil analisis Uji $\mathrm{t}$ diketahui nilai sig sebesar 0.002, dari hasil tersebut dapat diketahui sig $(0.002)<\alpha(0,05)$ artinya $\mathrm{H} 0$ ditolak dan Ha diterima. Dengan demikian dapat disimpulkan bahwa secara parsial atau individu variabel Assurance (Jaminan) berpengaruh positif dan signifikan terhadap loyalitas pelanggan. Hal ini berarti semakin meningkat Assurance (Jaminan) berupa reputasi toko yang terjamin seperti tidak pernah mencurangi pelanggan karena sekali mencurangi pelanggan maka nama baik toko pun akan rusak dan informasi akan mudah tersebar dari mulut ke mulut, kompetensi dan kemampuan karyawan dalam melayani yang berarti karyawan harus mengetahui barang-barang yang ada di toko serta letaknya karena ini akan mempermudah karyawan apabila ada pelanggan yang bertanya dan keramahan karyawan dan pemilik dalam memberikan layanan maka akan semakin meningkat loyalitas pelanggan pada Toko Tita Lubuk Buaya Padang.

\section{PENUTUP}

Dari hasil penelitian yang dilakukan mengenai pengaruh Tangible, Emphty, Reliability, Responsiveness dan Assurance terhadap loyalitas pelanggan pada Toko Tita di Lubuk Buaya Kota Padang, maka dapat ditarik beberapa kesimpulan sebagai berikut :

a. Koefisien regresi variabel Tangible (Bukti Fisik) sebesar 0.224 dan hasil analisis Uji $\mathrm{t}$ diketahui nilai sig sebesar 0.000 , dari hasil tersebut dapat diketahui sig $(0.000)<\alpha(0,05)$ artinya 
H0 ditolak dan Ha diterima. Dengan demikian dapat disimpulkan bahwa secara parsial atau individu variabel Tangible (bukti fisik) berpengaruh positif dan signifikan terhadap loyalitas pelanggan.

b. Koefisien regresi variabel Emphaty (Empati) sebesar 0.238dan hasil analisis Uji $t$ diketahui nilai sig sebesar 0.004, dari hasil tersebut dapat diketahui sig $(0.004)<\alpha(0,05)$ artinya H0 ditolak dan $\mathrm{Ha}$ diterima. Dengan demikian dapat disimpulkan bahwa secara parsial atau individu variabel Emphaty (Empati) berpengaruh positif dan signifikan terhadap loyalitas pelanggan.

c. Koefisien regresi variabel Reliability (Kehandalan) sebesar 0.226 dan hasil analisis Uji $t$ diketahui nilai sig sebesar 0.001, dari hasil tersebut dapat diketahui sig $(0.001)<\alpha(0,05)$ artinya $\mathrm{H} 0$ ditolak dan Ha diterima. Dengan demikian dapat disimpulkan bahwa secara parsial atau individu variabel Reliability (Kehandalan) berpengaruh positif dan signifikan terhadap loyalitas pelanggan.

d. Koefisien regresi variabel Rsponsiveness (Daya Tanggap) sebesar 0.225 dan hasil analisis Uji $\mathrm{t}$ diketahui nilai sig sebesar 0.004, dari hasil tersebut dapat diketahui sig $(0.004)<\alpha(0,05)$ artinya H0 ditolak dan Ha diterima. Dengan demikian dapat disimpulkan bahwa secara parsial atau individu variabel Responsiveness (Daya Tanggap) berpengaruh positif dan signifikan terhadap loyalitas pelanggan.

e. Koefisien regresi variabel Assurance (Jaminan) sebesar 0.229 dan hasil analisis Uji $t$ diketahui nilai sig sebesar 0.002, dari hasil tersebut dapat diketahui sig $(0.002)<\alpha(0,05)$ artinya HO ditolak dan Ha diterima. Dengan demikian dapat disimpulkan bahwa secara parsial atau individu variabel Assurance (Jaminan) berpengaruh positif dan signifikan terhadap loyalitas pelanggan.

\section{DAFTAR PUSTAKA}

10.22202/economica.2014.v3.i1.237

Aryani, Dwi dan Rosinta, Febrina. 2010. Pengaruh Kualitas Layanan terhadap Kepuasan Pelanggan dalam Membentuk Loyalitas Pelanggan. Jurnal Bisnis dan Birokrasi.Jurnal Ilmu Administrasi dan Organisasi, Mei Agust 2010, hlm 114-126.Vol. 17 No 2.ISSN 0854-3844.

Cornelia, Ellys dan Kartika, Wijaya.2008. Analisis Pengaruh Kualitas Layanan terhadap Loyalitas Pelanggan di Laundry 5ASEC Surabaya.Jurnal Manajemen Perhotelan Vol. 4 NO. 2 September 2008 :45-47.

Hasan, Ali. 2013. Marketing dan KasusKasus Pilihan.Cetakan Pertama. Yogyakarta: CAPS (Center For Academic Publishing Service).

Johnson, D.M. $1997 . \quad$ Customer Orientation and Market Action.Englewood Cliffs. New Jersey : Prectice Hall International inc.

Sugiyono. 2013. Metode Penelitian Kuantitatif, Kualitatif dan $R$ \& $D$. Cetakan ke 18. Bandung: Alfabeta, CV. Singgih, Santoso. 2005. Menguasai Statistik di Era Informasi dengan SPSS 13. Jakarta : PT. Elex Media Komputindo.

Tjiptono, Fandy. 2000. Manajemen jasa. Edisi Pertama, Cetakan Kedua. Yogyakarta : Andi.

Tjiptono, Fandy. 2008. Service management: Mewujudkan Layanan Prima. Yogyakarta : Andi 